\title{
Quality of vision in refractive and cataract surgery, indirect measurers: review article
}

\author{
Qualidade visual em cirurgia refrativa e catarata, medidores indiretos: artigo de revisão
}

\author{
Taís Renata Ribeira Parede ${ }^{1}$, André Augusto Miranda Torricelli ${ }^{1}$, Adriana Mukal ${ }^{2}$, Marcelo Vieira Netto ${ }^{1}$, Samir Jacob Bechara ${ }^{1}$
}

\begin{abstract}
Visual acuity is the measurement of an individual's ability to recognize details of an object in a space. Visual function measurements in clinical ophthalmology are limited by factors such as maximum contrast and so it might not adequately reflect the real vision conditions at that moment as well as the subjective aspects of the world perception by the patient. The objective of a successful vision-restoring surgery lies not only in gaining visual acuity lines, but also in vision quality. Therefore, refractive and cataract surgeries have the responsibility of achieving quality results. It is difficult to define quality of vision by a single parameter, and the main functional-vision tests are: contrast sensitivity, disability glare, intraocular stray light and aberrometry. In the current review the different components of the visual function are explained and the several available methods to assess the vision quality are described.
\end{abstract}

Keywords: Vision; Refractive surgical procedure; Cataract extraction; Contrast sensitivity; Vision, ocular/physiology; Aberrometry; Vision tests

\section{RESUMO}

Qualidade Visual é a medida da capacidade individual de reconhecer detalhes de um objeto no espaço. Medições de função visual na clínica oftalmológica são limitadas por vários fatores, tal como máximo contrastee assim podem não refletir adequadamente as condições visuais reais, bem como os aspectos subjetivos da percepção do mundo pelo paciente. O sucesso em uma cirurgia está não apenas em restaurar linhas de visão, mas sim qualidade visual. Portanto, as cirurgias refrativas e de catarata têm a responsabilidade de alcançar resultados de qualidade. Édifícil definir qualidade visual por um único parâmetro, sendo os principais testes de função visual: sensibilidade ao contraste; glare; dispersão intraocular da luze aberrometria. Nesta revisão os diferentes componentes da função visual são explicados e os diversos métodos disponíveis para se avaliar a qualidade de visão são descritos.

Descritores: Visão: Procedimentos cirúrgicos refrativos; Extração de catarata; Sensibilidades de contraste; Visão ocular/fisiologia; Aberrometria; Testes visuais

\section{INTRODUCTION}

Visual acuity measures the ability to recognize object details. Once it is measured under controlled distance, light and contrast conditions, visual acuity does not reflect the real quality of vision. External factors as indirect light can affect this quantitative assessment. Clinical ophthalmology commonly uses visual acuity optotypes only in order to assess the entire visual function ${ }^{(1)}$

Several previous epidemiological and clinical studies rely of visual functions measurements as the primary outcome, despite these measurements are crucial to understand the real patient's visual ability. Visual acuity does not express the real vision conditions and the subjective aspects of world perception by the patient ${ }^{(2)}$

The most common vision quantification test is the spatial determination of visual acuity through the Snellen chart. Letters displayed have two basic characteristics: size and contrast ${ }^{(3)}$. This test assesses the smallest identified font, keeping constant the black letters high contrast relative to the white background on which they are displayed. The degree of visibility of a given figure may be altered by reducing its contrast to a level which it is no longer recognized, regardless its size ${ }^{(4)}$.

In view of the fact that excellent visual acuity is expected from cataract and refractive surgery, the need for measurement of broader aspects of visual function has increased. Some patients with moderate visual acuity preoperatively might not be prepared to accept a postoperative visual acuity that, despite being good, is blurred by troublesome glare or disturbed by loss of contrast sensitivity. When a patient complains of glare, there are distinct visual phenomena he might be complaining of(5).
Quality of vision is difficult to define by a single parameter. Some patients are dissatisfied with their quality of vision after excimer laser refractive surgery even though their Snellen acuity is 20/20 (1.0) or better. Higher-order aberrations, image degradation, and contrast acuity have been implicated as reasons for patient's dissatisfaction ${ }^{(6)}$. Glare disability is another parameter that correlates with visual complaints after refractive surgery ${ }^{(7)}$.

The purpose of this review is to explain the different components of the visual function and to describe available methods to assess the aspects of quality of vision.

\section{FUNCTIONAL VISION}

Functional vision is our everyday vision. Different tasks in our daily life use different parts of our visual system. It reflects our vision in realworld situations, where we have to see both smaller high-contrast images and larger low-contrast ones. Our cognitive perception, the health of our visual system and our brain processing function, all play critical roles on how well we see the world ${ }^{(8)}$

Vision scientists are particularly concerned with how well the eye's retina transforms a visual image into neural code. That is how our eyes work with our brain to translate images into visual perception ${ }^{(9-13)}$.

The retina/brain system also filters the image into different sizes and levels of contrast ${ }^{(10,11)}$. Many properties come into play at the cortical level that impacts the final process of the visual information. These include attention, expectancy, memory, identification and other cognitive perceptual properties. When examining the comple-
Funding: No specific financial support was available for this study.

Disclosure of potential conflicts of interest: T.R.R.Parede, None; A.A.M.Torricelli, None; A.Mukai, None; M.V. Netto, None; S.J.Bechara, None.

Correspondence address: Taís Renata Ribeira Parede. Avenida Doutor Enéas de Carvalho Aguiar, 155 - Instituto Central - 6o andar - Departamento de Oftalmologia / Setor de Cirurgia Refrativa São Paulo (SP) - 05403-000 - Brazil - E- mail: taisparede@hotmail.com 
xity of our visual system, it is easy to see how the quality of input can impact the quality of our visual experience ${ }^{(10,11)}$.

A channel model represents how different vision cells, or channels, handle different aspects of vision, such as color, size, shape, contrast and motion. Each visual channel collects different bits of information for these varying aspects of vision and individually transmits them to the brain to be processed and assembled into a complete picture ${ }^{(8)}$.

Everything we see is broken down into a range of spatial frequencies, or channels. Channels are size-selective. Our visual system uses these different channels to see in high- and low-contrast situations. Our visual perception is the combination of all these channels $s^{(8,9)}$.

The channels that are used to see the letters on the 20/20 visual acuity test might be different from that ones that help us to see objects in our everyday lives. Because these channels are independent from each other, we need to test the sensitivity of each channel separately to determine how well different-size objects are seen ${ }^{(8,14)}$.

\section{FUNCTIONAL VISION PERFORMANCE TESTS}

The clinical evaluation of the quality of vision performance before and after an ophthalmologic surgery includes: the ability to detect contrasts; vision in different light levels; aberrations.

\section{Contrast Sensitivity $(8,9,11)$}

Contrast sensitivity refers to the ability of the visual system to distinguish between an object and its background. According to the channel model of vision, size-selective contrast cells are used to detect the differences between light and dark parts of an object and the background against which it is seen.

There are different available tests for the evaluation of contrast sensitivity. The main difference among them is the target type.

Charts that use letters, numbers or symbols in decreasing contrast are usually called low-acuity contrast tests, while those that use circles with bars or waves are called contrast sensitivity tests. For each kind of test, the least amount of contrast that can be perceived by an observer is displayed in graphs created by the manufacturers themselves, giving rise to the "line of contrast sensitivity" for each patient and the patient's ability to distinguish contrast sensitivity in relation to the normal range.

In some tests, depending on the logarithmic scale of contrast sensitivity, the patient might be classified as having normal vision, visual impairment or low vision.

There are two kinds of contrast sensitivity tests presently employed: grating tests and letter contrast sensitive.

\section{Sine-wave gratings tests ${ }^{(8-10)}$}

Sine-wave gratings (Figure 1) are used to create and test the contrast sensitivity curve. A sine-wave grating is a repeated number of fuzzy dark and light bars, or cycles. The number of grating cycles over a specified visual angle determines its spatial frequency.

A small number of cycles over a specified visual angle are defined as having a low spatial frequency. A large number of them over the same visual angle are defined as having a high spatial frequency. Contrast is the difference between the grating's brightness and darkness.

The visual system filters the images we see into independent ranges of sizes, or spatial frequencies. In vision testing, sine-waves of varying spatial frequencies (sizes) and contrast are needed to test the visual channels involved in functional vision.

The most commonly used tests are: Vision Contrast Test System (VCTS 6500 e 6000) (Vistech, Dayton, OH), Contrast Sensitivity Vision (CSV 1000 E) (VectorVision, Greenville, OH) and Functional Acuity Contrast Test (FACT) (Vision Science Research Corporation, Walnut Creek, California).

Environment conditions considerations to grating tests are shown on table 1.

\section{Letter contrast sensitivity ${ }^{(8,9,13)}$}

Letter contrast sensitivity (Figure 2) is similar to low-contrast acuity in that the patient's task is to read as many letters as possible from a chart. Although in the contrast sensitivity test all letters have the same size and are large enough to be legible whenever they can be seen at all, their contrast is progressively reduced, from near 100\% at the top of the chart, to near $0 \%$ at its bottom.

The ability to see low-contrast letters is important for reading signs and identifying low-contrast objects that are similar in size to the test letters. However, letter contrast sensitivity test results may not be inferred to real life situations that involve detection and recognition of objects that are either much larger or much smaller than the chart letters.

The most commonly used tests are: Test Bailey-Lovie Chart or Regan (The National Vision Research Institute, Australia), that use Early Treatment Diabetic Retinopathy Study (ETDRS) Chart (Precision Vision) and Pelli-Robson (Haag-Streit, Mason, $\mathrm{OH}$, USA).

Environment considerations to letter tests are also shown on table 1.

\section{Which CONTRAST SENSITIVITY TEST IS THE BEST?}

A comparison of Contrast Sensitivity Tests Research shows that the "Contrast Sensitivity Curve" provided by sine-wave grating tests is more sensitive and informative than the results obtained from lowcontrast letter-acuity systems ${ }^{(8)}$.

Some investigators believe grating tests of contrast sensitivity are superior to letter contrast sensitivity charts. Their arguments emphasize that, in clinical research, it is important to assess the broad contrast sensitivity function from low to high spatial frequencies, as this function reflects the visual system's multiple spatial filters ${ }^{(15)}$.

A number of authors have concluded that test-retest reliability of the sine-wave grating tests may be problematic for their intended purpose of screening and tracking change ${ }^{(15-18)}$. The good test-retest reliability of the letters chart, relative immunity from varying test conditions, ease the brevity of administration (3-5 minutes), and availability of published normative data ${ }^{(19)}$, have led to its frequent choice for epidemiological studies ${ }^{(20-23)}$

\section{Vision in different light leVels - "Glare test" \\ Disability glare}

It refers to the temporary loss of visual function in the presence of a bright adjacent light source. Common sources of disability glare for

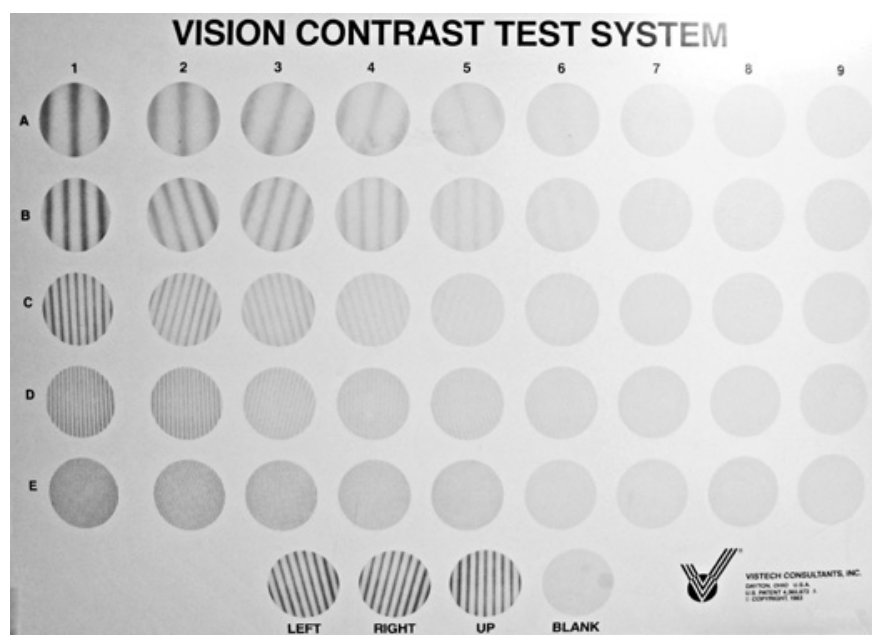

Figure 1. $F A C T$ sine-wave grating chart tests five spatial frequencies (sizes) and nine levels of contrast. The patient determines the last grating seen for each row $(A, B, C, D$ and $E)$ and reports the orientation of the grating: right, up or left. The last correct grating seen for each spatial frequency is plotted on a contrast sensitivity curve. 
Table 1. Comparison of Contrast Sensitivity test and Glare test methodologies

\begin{tabular}{|c|c|c|c|}
\hline Methodology & Tests & Pros & Cons \\
\hline \multicolumn{4}{|c|}{ Contrast sensitivity } \\
\hline Sine-waves grating tests & $\begin{array}{c}\text { VCTS } 6500 \\
\text { VCTS } 6000 \\
\text { CSV } 1000 E \\
\text { FACT }\end{array}$ & $\begin{array}{l}\text { Assesses the whole contrast sensitivity function } \\
\text { from lowest to highest spatial frequencies }\end{array}$ & $\begin{array}{l}\text { Time consuming; results are more variable } \\
\text { than standard acuity test results }\end{array}$ \\
\hline $\begin{array}{l}\text { Letter contrast sensitivity } \\
\text { (ETDRS Charts) }\end{array}$ & $\begin{array}{l}\text { BAILEY-LOVIE } \\
\text { REGAN }\end{array}$ & $\begin{array}{c}\text { Quick, easy, good predictor of performance for } \\
\text { high resolution tasks under bright } \\
\text { and low light conditions }\end{array}$ & $\begin{array}{l}\text { If photopic conditions: Poor predictor of performance under low } \\
\text { contrast conditions. If mesopic condition: Test conditions difficult to } \\
\text { control and results are more variable than photopic results }\end{array}$ \\
\hline Letter contrast sensitivity & PELLI-ROBSON & $\begin{array}{l}\text { Assesses performance for } \\
\text { reading low contrast signs }\end{array}$ & $\begin{array}{l}\text { May not provide an accurate assessment of performance detecting } \\
\text { and recognizing objects with sizes different than the chart letters }\end{array}$ \\
\hline
\end{tabular}

Glare test

\begin{tabular}{|c|c|c|c|}
\hline Disability glare & $\begin{array}{l}\text { OPTEC } 6500 \\
\text { CST } 1800 \\
\text { CSV } 1000 \mathrm{HGT}\end{array}$ & $\begin{array}{l}\text { Adding glare testing to vision tests adds } \\
\text { information about the effects of intraocular light } \\
\text { scatter on visual performance }\end{array}$ & $\begin{array}{l}\text { Time consuming; results are more variable } \\
\text { than standard acuity test results }\end{array}$ \\
\hline Intraocular straylight & C- QUANT & Fast, easy for the patient, and accurate & $\begin{array}{l}\text { Correlation between straylight results and other vision tests with } \\
\text { glare, and driving performance not yet established }\end{array}$ \\
\hline
\end{tabular}

VCTS= vision contrast test system; CSV= standardized contrsts sensitivity; FACT= functional acuity contrast test; ETDRS= Early Treatment Diabetic Retinopathy Study; CST= contrast sensitivity tester; C-Quant= cataract-quantifier.

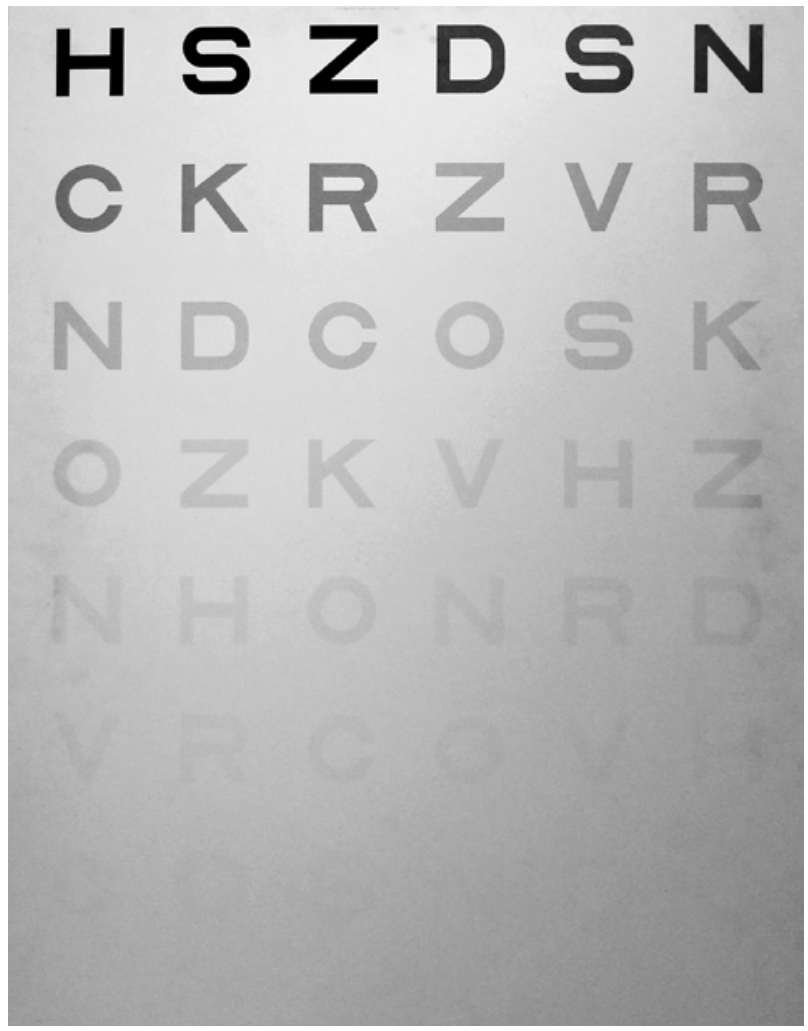

Figure 2. Pelli-Robson test measures contrast sensitivity using a single large letter size (20/60 optotype), with contrast varying across groups of letters. Specifically, the chart uses letters (6 per line), arranged in groups whose contrast varies from high to low. Patients read the letters, starting with the highest contrast, until they are unable to read two or three letters in a single group. Each group has three letters of the same contrast level, so there are three trials per contrast level. The subject is assigned a score based on the contrast of the last group in which two or three letters were correctly read. The score, a single number, is a measure of the subject's log contrast sensitivity. Thus a score of 2 means that the subject was able to read at least two of the three letters with a contrast of 1 percent (contrast sensitivity $=100$ percent or $\log 2$ ). A Pelli-Robson score of 2.0 indicates normal contrast sensitivity of 100 percent. Scores less than 2.0 signify poorer contrast sensitivity. Pelli-Robson contrast sensitivity score of less than 1.5 is consistent with visual impairment and a score of less than 1.0 represents in visual disability. drivers are the sun and headlights from oncoming cars. Susceptibility to glare sources varies greatly from person to person, depending on the amount of light that is scattered into the retina from the crystalline lens and other eye structures. A clinical test that could accurately predict the effects of glare and light-scattering sources on driving performance should be a valuable diagnostic tool for evaluating new medical products that physically produces the light scatter or affects how one realizes the intraocular light scatter. Several disability glare tests have been developed for clinical use ${ }^{(24-25)}$.

In most tests, especially those that involve measuring contrast sensitivity or visual acuity in the presence of a continuous, static glare source, its light may cause the pupil to constrict enough to affect the results of the glare measurement ${ }^{(26)}$.

Advantage of these tests is that they eliminate the needs to contro the levels of room light and can be used in a small space (Table 1) ${ }^{(27)}$.

Available tools to measure disability glare are: Optec 6500 P (Stereo Optical Company, Inc, Chicago, Illinois, USA), CST 1800 digital (Vision Sciences Research Corporation, Walnut Creek, California) and CSV 1000HGT (VectorVision, Greenville, OH).

\section{Intraocular stray light}

A different approach to assess the effects of disability glare on visual function is to obtain a direct measurement of the amount of stray light in the eye produced by a glare source. Oculus Instruments (Oculus, Optikgeräte, Wetzlar- Dutenhofen, German) have recently marketed the C-Quant Stray light Meter ${ }^{\circledR}$ (Figure 3) developed by van den Berg and ljspeert ${ }^{(28-30)}$.

The device, currently marketed in the United States, effects a temporal variation in the stray light from a flickering glare source, which is nullified by a superposed light flickering out of phase with the stray light. The amount of added light that just cancels out the stray light flicker is a direct measurement of the stray light. The test is fast, easy for the patient, and accurate. However, the correlation between the straylight results from this test and the results of contrast sensitivity with glare tests and the real life conditions, have not been established ${ }^{(2)}$.

\section{Aberrometri $^{(31)}$}

Aberrometry allows the objective evaluation of visual quality. It is a technological modality that studies the propagation of light from the physical optic analysis. In an optical homogeneous system the 


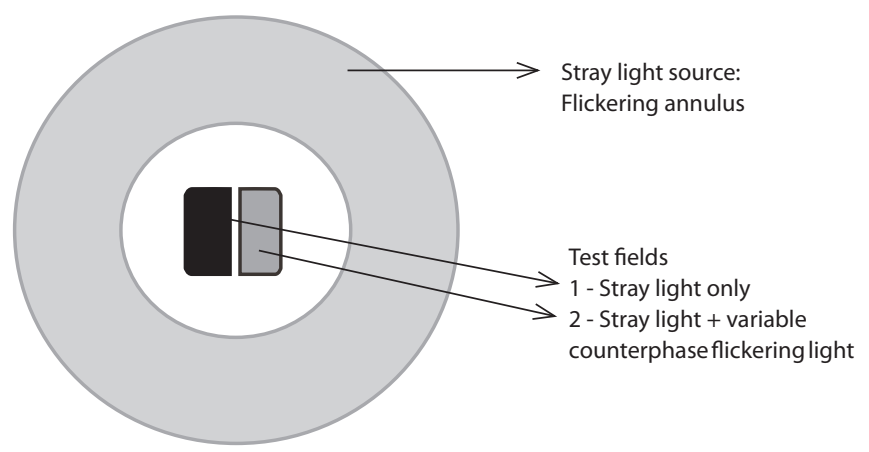

Figure 3. Example of a patient's view of a straylight test, modified from van den Berg et al. ${ }^{(24)}$. The patient is presented with two alternative forced choices and asked to choose between the stronger of two flickers presented in controlled background lights. The test duration is one to two minutes per eye. The straylight test has an internal analysis procedure that yields a reliability estimate called the expected standard deviation (ESD), which was developed to control and increase the internal reliability of the test. Only reliable test results (ESD $\leq 0.08$ log units) should be accepted.

light propagates uniformly from a point of light, at the same speed in all directions. When this wavefront hits on an ideal lens, it creates a single focal point. In real lenses, the spread of the wavefront is modified, so paracentral and peripherals rays propagate in several wavefronts, not coinciding in a single focal point. This phenomenon is known as monochromatic aberration.

The human eye is not a perfect optical system, but the aberrations can be partially compensated due to the aspherical corneal shape and the asphericity of the lens, that bring an attenuation of optical aberrations.

The wavefront analysis measures the difference between the aberrations of a real wavefront, measured in an optical system and an ideal wavefront, through an ideal optical system. These differences are the characteristic of each optical system, of each human eye.

The optical aberrations that can be corrected are the monochromatic ones (which have a single wavelength of visible light), and these can be quantitatively schematized in Zernike Polynomial. This polynomial describes the wavefronts in three dimensions: $x, y$ and $z$. Thus, the final wavefront of an optical system is the sum of Zernike Polynomials that represents all strains of this system.

In the Polynomial, the aberrations are decomposed in lower order aberrations (zero until second order) and higher order aberrations (third until tenth order).

Lower order aberrations, denominated tilt, defocus and astigmatism, represent $85 \%$ of the total ocular aberrations in normal eyes and are able to be corrected by spherocylindrical optical systems or conventional refractive surgery.

Higher order aberrations represent $15 \%$ of ocular aberrations in normal eyes. There are aberrations that limit vision, and can not be corrected with spherocylindrical lenses or conventional refractive surgeries. The most relevant are coma, spherical aberration, trefoil and tetrafoil.

It is believed that higher order aberrations are responsible for a number of visual complaints present even in patients with normal visual acuity in the tables for high contrast. Complaints include the presence of halo, glare, double vision and star burst symptoms, especially at night when the dilated pupil provides greater incidence of high order aberrations in the optical system of the eye ${ }^{(32)}$.

Higher-order aberrations can be expressed numerically by the root mean square (RMS), which measures the difference between a wavefront in a real optical system and an ideal optical system. The RMS represents a reliable measurement of the amount of aberration of an optical system, is generic and does not specify the qualitative characteristics of each aberration found.

There are, however, other aberrometric indices that measure the quality of the images generated by an optical system, such as
Point spread function (PSF), Strehl ratio, and Modulation transfer function (MTF).

\section{Point spread function}

Measure how the retina views the point image after traversing the optical system of the eye. It is graphically represented as a distortion of a point on the retina varying with the captured area and the pupilary diameter.

\section{Strehl ratio}

Contrast measurement defined by the ratio between the PSF of an optical system and the PSF of a perfect optical system (limited only by diffractions). The Strehl ratio value greater than or equal to 0.8 is considered to be perfect, representative of an optical system without aberrations. However, in the normal population, influenced by pupil size, their values are close to zero.

\section{Modulation transfer function}

Attempts to measure image contrast. It evaluates the ability of a system to convert an object contrast to the image plane, at a specific resolution. In other words, it analyzes the image contrast as a function of frequency.

\section{SYSTEMS OF WAVE FRONT ANALYSIS}

The system of wavefront analysis can be ingoing or outgoing. The ingoing system studies the aberrations of the light beams projected on the retina. The outgoing system evaluates the wave front coming out of the eye from a light beam projected toward the retina and reflected back. Thus, aberrometers can be classified according to their standard operation: outgoing and ingoing system ${ }^{(28)}$.

\section{Outgoing SYstem ${ }^{(33)}$}

- Hartmann-Shack Sensor (Zywave - Baush \& Lomb; WaveScan VISX; Wasca Analyser - Carl Zeiss-Meditec; KR-9000PW -Topcon; Maxwel - Ziemer Ophthalmology).

\section{INGOING SYSTEM ${ }^{(33)}$}

\section{Retinal imaging systems}

- System ofTschening (WaveLight Wavefront Analyser - WaveLight; ORK Wavefront Analyser-Schwind)

- Ray Tracing (Trace VFA; i-Trace-Tracey)

\section{Double pass system}

- Slit retinoscopy (OPD- Scan - Nidek; OQAS- Visopmetrics S.L.)

The quantitative and qualitative information provided by the study of the wavefront of each human eye, can help to decode each optical system separately and proceed surgically to reduce the high order aberrations, providing better visual quality to the patient. It is the custom refractive surgery, based on aberrometrical discrimination, in the wavefront analysis of each human eye ${ }^{(34)}$.

\section{FINAL CONSIDERATIONS}

Our cognitive perception, the health of our visual system, and the processing function of our brain all play critical roles on how well we see the world. Vision researchers are still developing better tests to analyze visual system and to understand all variables involved in the visual acuity ${ }^{(8)}$.

The current objective of a successful vision-restoring eye surgery is not only to gain lines in visual acuity, but also to achieve quality of vision. Therefore, refractive and cataract surgeries aim higher quality standards for their results. 
A detailed patient's clinical history, his visual demands and ophthalmological characteristics at the preoperative clinical examination are important in planning a successful surgery. Besides the diagnosis of lens opacity or refractive error to be corrected, contrast sensitivity, glare and wavefront analysis (aberrometry) should also be considered when planning a surgical procedure.

When evaluating the safety and effectiveness of medical products, it is important to assess their effects on the performance of "real-world" visual tasks. However, tests of visual performance are not yet standardized, and no consensus has been reached on the ability of existing clinical vision tests to predict real-world performance ${ }^{(28)}$.

Most currently available clinical vision tests were developed as general-purpose diagnostic tests for visual system disorders. Specific validation studies are still needed to identify individual tests or combinations of them that might accurately and consistently predict visual performance.

Assessment of visual performance is often important in evaluating the safety and effectiveness of new drugs and medical devices, but it is typically complex, expensive and burdensome for subjects and investigators. Identification of clinical tests that could serve as acceptable reference for visual-performance tests in clinical trials would yield major savings of time, effort, and expense in the evaluation of new products.

Studies that isolate the visual aspects of performance should increase the chances of revealing their true correlations with clinical measures of visual function ${ }^{(28)}$.

Given all the technology available today to achieve excellence in visual quality, such as customized refractive surgery, aspheric, toric and intraocular phakic lens, should it be satisfactory to rely on just one visual acuity, high-contrast test, without further relevant information about the optical system of each patient? So how to take advantage of all current available technology?

Perhaps spending more time on patient evaluation, using tests that provide valuable information on the particular characteristics of each optical system, and so improving our clinical and surgical decisions to meet the patient's expectations.

\section{REFERENCES}

1. Dick HB, Krummenauer F, Schwenn O, Krist R, Pfeiffer N. Objective and subjective evaluation of photic phenomena after monofocal and multifocal intraocular lens implantation. Ophthalmology. 1999;106(10):1878-86.

2. Massof RW, Rubin GS. Visual function assessment questionnaires. Surv Ophthalmol. 2001;45(6):531-48.

3. Wolfe JM. An introduction to contrast sensitivity testing. In: Nadler MP, Miller D, Nadler DJ, editors. Glare and contrast sensitivity for clinicians. New York: Springer-Verlag; 1990. p.5-23.

4. Monteiro ML. Contribution to the study of contrast sensitivity in patients with hemianopsia deficiency attributed to pituitary tumors [Tese]. São Paulo: Faculty of Medicine; Universidade de São Paulo; 1992.

5. Koch DD. Glare and contrast sensitivity testing in cataract patients. J Cataract Refract Surg. 1989;15(2):158-64.

6. Fan- Paul NI, Li J, Sullivan Miller J, Florakis GJ. Night vision disturbances after corneal refractive surgery. Surv Ophtalmol. 2002;47(6):533-46.

7. Vignal R, Tanzer D, Brunstetter T, Schalllhom S. [Scattered light and glare sensitivity after wavefront-guided photorefractive (WFG-PRK) and laser in situ keratomileusis]. J Fr Ophtalmol. 2008;31(5):489- 93.
8. Ginsburg AP. Contrast sensitivity and functional vision. Int Ophthalmol Clin. 2003 43(2):5-15.

9. Ginsburg AP. Spatial filtering and visual form perception. In: Boff K, editot. Handbook of perception and human performance. New York: John Wiley \& Sons; 1986. p.77-88.

10. Campbell FW, Robson JG. Application of Fourier analysis to the visibility of gratings J Physiol.1968;197(3):551-66.

11. Ginsburg AP. Spatial filtering and vision: implications for normal and abnormal vision. In: Proenza LM, Enoch JM, Jampolsky A, editors. Clinical applications of visual psychophysics. Cambrige: Cambridge University Press; 1981. p.70-106.

12. DeValois RL, DeValois KK. Spatial vision. Ann Rev Psychol.1980:31:309-41.

13. Ginsburg AP. Next general contrast sensitivity testing. In: Rosenthal B, Cole R, editors. Functional assessment of low vision. St Louis: Mosby Year Book; 1996. p.77-88.

14. Ginsburg AP. Forensic aspects of visual perception. In: Allen MJ, Abrams BS, Ginsburg AP, Weintraub L. Forensic aspects of vision and highway safety. Tucson, Arizona: Lawyers \& Judges Publishing; 1996. p.201-40.

15. Owsley C. Contrast sensitivity. Ophthalmol Clin North Am. 2003; 16(2):171-7.

16. Elliott DB, Bullimore MA. Assessing the reliability, discriminative ability, and validity of disability glare tests. Invest Ophthalmol Vis Sci. 1993:34(1):108-19.

17. Reeves BC, Wood JM, Hill AR. Vistech VCTS 6500 charts within-and-between session reliability. Optom Vis Sci. 1991;68(9):728-37.

18. Rubin GS. Reliability and sensitivity of clinical contrast sensitivity tests. Clin Vision Sci. 1988;2:169-77.

19. Elliott DB, Sanderson K, Conkey A. The reliability of the Pelli-Robson contrast sensitivity chart. Ophthalmic Physiol Opt. 1990;10(1):21-4. Comment in: Ophthalmic Physiol Opt. 1992;12(1):111-5

20. Brabyn J, Schneck M, Haegerstrom-Portnoy G, Lott L. The Smith-Kettlewell Institute (SKI) longitudinal study of vision function and its impact among the elderly: an overview. Optom Vis Sci. 2001;78(5):264-9.

21. Klein BE, Klein R, Lee KE, Cruikshanks KJ. Associations of performance-based and self-reported measures of visual function: the Beaver Dam Eye Study. Ophthalmic Epidemiol. 1999;6(1):49- 60.

22. Owsley C, Stalvey BT, Wells J, Sloane ME, McGwin G Jr. Visual risk factors for crash involvement in older drivers with cataract. Arch Ophthalmol 2001;119(6):881-7.

23. Rubin GS, West SK, Munoz B, Bandeen-Roche S, Zeger S, Schein O, et al. A comprehensive assessment of visual impairment in a population of older Americans. The SEE Study. Salisbry Eye Evaluation Project. Invest Ophthalmol Vis Sci. 1997;38(3):557-68.

24. Van den Berg TJ, Franssen L, Kruijt B, Coppens JE. History of ocular straylight measurement: A review. Z Med Phys. 2013;23(1):6-20.

25. Elliott DB. Evaluating visual function in cataract. Optom Vis Sci. 1993;70(11):896-902

26. Aslam TM, Haider D, Murray IJ. Principles of disability glare measurement: an ophthalmological perspective. Acta Ophthalmol Scand. 2007;85(4):354-60.

27. Drum B, Calogero D, Rorer E. Assessment of visual performance in the evaluation of new medical products. Drug Discovery Today: Technologies [Internet]. 2007 [cited 2012 Jan 3]:4(2):55-61.Available from: http://www.sciencedirect.com/science/article/ pii/S1740674907000169

28. Ijspeert JK, van den Berg TJ. Design of a portable straylight meter. Presented at: $14^{\circ}$ Annual International Conference IEEE Engineering in Medicine and Biology; 1992 Oct 29-Nov 1. Paris p.1592-4. Proceeding.

29. Van den Berg TJ, ljspeert JK. Clinical assessment of intraocular straylight. Appl Opt 1992;31(19):3694-6.

30. Van Rijn LJ, Nischler C, Gamer D, Franssen L, de Wit G, Kaper R, et al. Measurement of stray light and glare: comparison of Nyktotest, Mesotest, stray light meter, and computer implemented stray light meter. Br J Ophthalmol. 2005;89(3):345-51.

31. Barreto J Jr. Aberrometria. In: Bechara SJ, Garcia R, Medeiros FW, Barreto J Jr, Vieira Netto M. Guia prático de cirurgia refrativa. Porto Alegre: Artmed; 2009. p.85-7.

32. Athaide HV, Campos M, Costa C. Study of ocular aberrations with age. Arq Bras Oftalmol. 2009;72(5):617-21.

33. Vieira Netto $M$, Ambrosio $R$ Jr. Introdução aos sistemas disponíveis de aberrometria ocular. In: Vieira Netto MV, Ambrosio R Jr, Schor P, Chalita MR, Chamon W, et al. Wavefront, topografia e tomografia da córnea e segmento anterior. Rio de Janeiro: Cultura Médica; 2006. p.251-2.

34. Barreiro TP, Forset Ados S, Pinto LF, Francesconi CM, Nosé W. [Wavefront-guided Lasik for low to moderate myopia: CustomCornea versus Zyoptix]. Arq Bras Oftalmol. 2009;72(4):519-25. 